\title{
AVANCE DE INVESTIGACIÓN
}

\section{VIVENCIA DE UNA COSMOVISIÓN APOCALÍPTICA EN IGLESIAS EVANGÉLICAS EN SITUACIÓN DE RIESGO SOCIAL DEL MUNICIPIO DE SANTA TECLA}

\author{
José Victor Villavicencio Ayala \\ Docente de la carrera de teología \\ Facultad de Ciencias Sociales \\ Universidad Evangélica de El Salvador \\ Recibido: 03/06/2015 \\ Aceptado: 10/11/2015
}

\section{RESUMEN}

Esta es una investigación de tipo etnográfico que se propone comprender de manera profunda las prácticas de los individuos bajo una cosmovisión apocalíptica en iglesias en situación de riesgo social del municipio de Santa Tecla. Estudios como este son importantes debido a la enorme difusión que tienen las ideas apocalípticas en los medios cristianos evangélicos. Se realizó observación participante de julio a septiembre del año 2015, al mismo tiempo que se sostuvieron algunas entrevistas con el pastor general de la iglesia y su liderazgo. El análisis de los datos permitió extender algunas recomendaciones generalizantes ya que Misión Cristiana Roca Eterna puede servir como modelo o parámetro para la vivencia de una cosmovisión apocalíptica integral, con conciencia social y ciudadana.

Palabras clave: Cosmovisión Apocalíptica, Riesgo Social, Conciencia Social, Conciencia Ciudadana, Santa Tecla, El Salvador.

\section{THE EXPERIENCE OF AN APOCALYPTIC COSMOVISION IN EVANGELICAL CHURCHES LIVING AT SOCIAL RISK IN THE CITY OF SANTA TECLA}

\begin{abstract}
This is an ethnographic research that seeks a deep understanding of the practices of individuals living under an apocalyptic cosmovision in churches at social risk from Santa Tecla. This type of research is relevant due to huge dissemination of apocalyptic views among evangelical Christians. Observation was conducted from July to September during the present year, besides interviewing senior pastors and church leaders. Through the data analysis it was possible to make some general recommendation since 'Mision Cristiana Roca Eterna' can be a role model or referent for living an integral apocalyptic cosmovision with social and civic awareness.
\end{abstract}

Key words: Apocalyptic cosmovision, Social Risk, Social Awareness, Civic Awareness, Santa Tecla, El Salvador. 


\section{INTRODUCCIÓN}

La apocalíptica es un fenómeno religioso que se constituye como una forma específica de ver y actuar en el mundo, y por tanto, se trata de una cosmovisión. Este fenómeno surgió en el judaísmo posexílico, en círculos judíos que se vieron afectados por una estructura social y religiosa que los excluyó. Este fue el caldo de cultivo para el surgimiento de ideas completamente nuevas acerca de Dios, los ángeles, el mundo, la historia, y el ser humano. Estas ideas apuntaban a que el fin del mundo acontecería muy pronto, en la época del vidente, y en forma de catástrofe. De esta manera, Dios pondría fin a una historia llena de corrupción e injusticia, inaugurando con ello un mundo nuevo donde los justos gobernarán de la mano con el Mesías de Israel. El apocalíptico se percibe enemigo de la estructura social, y totalmente ajeno a sus procesos.

Estas ideas estaban ampliamente difundidas en el tiempo de Jesús, en la Palestina del siglo I; según se puede verificar incluso por citas del Nuevo Testamento a textos apócrifos como el Libro de Enoc y la Asunción de Moisés. De hecho, la cosmovisión apocalíptica jugó un papel nefasto ya que alimentaba el espíritu revolucionario de los Zelotes que estalló en el año 66 d.C. con la revuelta en Jerusalén. Fue por esta y otras razones que el judaísmo rabínico excluyó la apocalíptica del canon del Antiguo Testamento cuando éste fue ratificado oficialmente en Yabne, en el año 100 d.C.

Sin embargo,laapocalípticaes unfenómeno religioso que ha conocido re-surgimientos en diferentes etapas de la historia del cristianismo. En la Reforma, por ejemplo, hubo un resurgir apocalíptico en personas como Martín Lutero y Thomas Müntzer. Así mismo, hubo un resurgimiento en medio de los movimientos puritanos del siglo XVI, y en los grandes avivamientos del siglo XIX y XX.

Al revisar el contexto social de los círculos apocalípticos, judíos y cristianos, de diferentes épocas, se puede advertir una relación causal entre las condiciones socioeconómicas de riesgo y el surgimiento de ideas apocalípticas. Estas ideas encontraron cabida en grupos sociales que se enfrentaban a situaciones de pobreza, marginalidad y represión por parte del poder político.

Es por este motivo que en la literatura apocalíptica se manifiesta, de una forma velada o simbólica, el descontento hacia la estructura social y la esperanza de que ésta sea sustituida por el reinado definitivo de Dios en la Tierra a favor de los pobres. Se imagina un mundo ideal donde todos y todas tienen acceso a recursos y privilegios para vivir de manera digna. Se comprende que las ideas apocalípticas surjan como rechazo hacia una estructura social que no garantiza la seguridad y el bienestar de los grupos afectados. Es por eso que la literatura apocalíptica juzga el sistema socio-económico vigente a través de sus elaboradas representaciones del fin del mundo en forma de catástrofe.

La idea de realizar un estudio como éste surgió debido a la enorme separación que hay entre la esperanza escatológica, según se vive en las iglesias evangélicas tradicionales, y el desarrollo de una conciencia social y ciudadana que conduce a acciones concretas a favor de la comunidad. Lo que se persigue es comprender de manera profunda cómo se nutren estas ideas apocalípticas en condiciones sociales específicas, y cómo estas ideas influyen en el estilo de vida de los individuos. 
Este intento por comprender la vivencia de lo apocalíptico reviste una profunda relevancia social, debido a la enorme difusión que estas ideas han alcanzado en el mundo evangélico protestante rural y urbano. El impacto de estas ideas se deja ver en la manera cómo los individuos se relacionan con las instituciones sociales y cuál es su grado de participación ciudadana en temas de relevancia para la comunidad.

Esta investigación se llevó a cabo en Misión Cristiana Roca Eterna, ubicada en 9a av. Sur, entre $4^{\underline{a}}$ y $2^{\underline{a}}$ calle Oriente, \#2-8, Santa Tecla, frente al Instituto Nacional José Damián Villacorta. El objetivo principal que persigue es comprender la vivencia de una cosmovisión apocalíptica en iglesias evangélicas en situación de riesgo social del municipio de Santa Tecla.

\section{METODOLOGÍA DE LA INVESTIGACIÓN}

El presente estudio es de tipo cualitativo ya que busca comprender cómo las ideas apocalípticas influyen en el comportamiento y mentalidad de los participantes, y sobre todo, en su actitud hacia la sociedad y sus instituciones. El abordaje general es etnográfico, y la profundidad del estudio es exploratoria. El diseño emergente de esta investigación ha permitido que las diferentes partes que la componen vayan siendo actualizadas o replanteadas con mucha flexibilidad, en la medida en que se va obteniendo un conocimiento más exacto del fenómeno de estudio. La técnica utilizada para recolectar datos ha sido la observación participante, y el instrumento respectivo el Diario de Campo.

\section{ANÁLISIS Y DISCUSIÓN DE RESULTADOS}

A partir de los datos descriptivos presentados en el apartado anterior se pueden interpretar las categorías y sus relaciones de la manera siguiente:

\section{Existe una relación entre los factores de riesgo social y la rica tradición apocalíptica.}

Esta es una iglesia enfrentada a todo tipo de situaciones de riesgo. La vulnerabilidad económica e inseguridad son los factores que más golpean a los miembros o feligreses de esta congregación. En los apuntes de la Observación $\mathrm{N}^{\circ} 4$, uno de los participantes señaló que la mayoría de los miembros de la iglesia carecen de un trabajo fijo y estable; por si fuera poco, se vive un ambiente de inseguridad debido a las pandillas y a la delincuencia generalizada. Estos mismos participantes son herederos de una rica tradición apocalíptica: hablan de la venida de Cristo, de las señales antes del fin, y de las recompensas del más allá.

Estas ideas apocalípticas se convierten en una fuente de consuelo y esperanza en medio de un contexto desesperanzador caracterizado por la vulnerabilidad en todos los ámbitos sociales. El contenido de la predicación del domingo 7 de septiembre del año 2015 responde con imágenes apocalípticas a la situación de pobreza que sufren los miembros (Observación $\mathrm{N}^{\circ} 7$ ): Les habla de calles de oro, y riquezas en el más allá como compensación por las carencias que ahora viven los cristianos en este mundo. La relación entre estas dos categorías aparece en el origen mismo de la apocalíptica, ya que ésta surge en círculo judíos y cristianos que enfrentaban pobreza, exclusión y represión por parte del Estado.

La imaginería apocalíptica aparece con más fuerza en los ambientes donde los creyentes se enfrentan a problemas sociales y económicos sobre los cuales no tienen control, y esperan una irrupción para salvación de parte de Dios. 


\section{Existe una relación entre dos men- talidades: la cosmovisión apocalíp- tica y la conciencia social. ${ }^{1}$}

Esta congregación se caracteriza por una arraigada cosmovisión apocalíptica que se refleja mayoritariamente en el lenguaje de los individuos. Por ejemplo, la vida está volcada al acontecimiento de la venida de Cristo, y los colaboradores hacen referencia a este teologuema en la mayoría de sus participaciones (Observación $\mathrm{N}^{\circ} 3$ ). Sin embargo, a pesar de que sus perspectivas espirituales están volcadas hacia el futuro, se podría decir que "tienen los pies sobre la tierra" ya que han adoptado una conciencia social que los motiva a desarrollar programas de beneficio para la comunidad.

Uno de estos programas consistió en adquirir equipo para la venta ambulante de café; así los miembros que están desempleados reciben la oportunidad de realizar una actividad que les asegura ingresos modestos (Observación $\mathrm{N}^{\circ} 6$ ). El pastor general también afirmó que han realizado campañas médicas en el pasado, sin la ayuda de otras instituciones $u$ ONG's. Esta relación entre la cosmovisión apocalíptica y la conciencia social es muy importante tomando en cuenta que, por lo general, siempre se identifica al apocalíptico como una persona que ignora o menosprecia la realidad, que está siempre con la mirada en el futuro y hace poco por su comunidad.

El caso particular de Misión Cristiana Roca Eterna es el de una apocalíptica integral.Sin embargo, como se explicará más adelante, la gran mayoría de los miembros entienden este enfoque de una manera diferente a como lo entiende el pastor general. Así

1 Entendida como el grado de conocimiento que una persona posee sobre la situación real de las personas que forman parte de su comunidad y la capacidad de acompañar la reflexión con la praxis. como se hace notar en la observación $\mathrm{N}^{\circ}$ 9, los miembros de esta iglesia hacen una labor social para que "Cristo los encuentre dando testimonio", más que por una auténtica toma de conciencia acerca de la realidad social, económica y cultural de su comunidad.

\section{Hay una relación de oposición entre el enfoque integral de la apocalíp- tica, representado por el pastor ge- neral; y el enfoque tradicional de la apocalíptica, representado en algu- nos sectores de la iglesia.}

El pastor general ha desarrollado un enfoque integral de la apocalíptica, es decir que ha sabido vincular las esperanzas futuristas con una preocupación social que lo ha llevado a desarrollar programas de beneficio para las comunidades. En la Observación $\mathrm{N}^{\circ} 6$, el pastor critica el terrorismo escatológico ${ }^{2}$ y la apocalíptica que sólo sirve para generar ilusiones y evadir la realidad. Los estudios de teología que ha cursado el Ptr. Gregorio López le ha permitido tener unas perspectivas teológicas más realistas; se nota mucho la influencia del teólogo estadounidense Juan Stam por sus expresiones y la manera de valorar los escritos apocalípticos.

Sin embargo, este enfoque integral no es compartido por todos los sectores de la iglesia. Esto quedó claro en la Observación $\mathrm{N}^{\circ} 7$-domingo 7 de septiembre de 2015-, cuando el predicador invitado predicó sobre cosas apocalípticas de la manera más tradicional. En su discurso resaltaban elementos como el dualismo, exclusivismo salvífico, y otros típicos de la apocalíptica. La acogida que tuvieron estas expresiones entre la congregación se pudo verificar por la intensidad de aplausos, y frases como

2 Actividad mediante la cual algunos predicadores aterrorizan a su congregación con imágenes de catástrofes y grandes desgracias tomadas del libro del Apocalipsis de Juan. 
¡Amén! 0 ¡Gloria a Dios! Por tanto, ciertos sectores de la iglesia aún ven el mundo y la realidad desde una perspectiva apocalíptica tradicional: como espera de fin del mundo inminente. Sin embargo, las perspectivas apocalípticas tradicionales de estos sectores no han impedido el desarrollo de los programas de beneficio a otros miembros de la iglesia, y a la comunidad en general.

Los autores han destacado como parte del universo apocalíptico las siguientes características: Dualismo, determinismo histórico, espera febril del fin del mundo, destrucción por medio de una catástrofe, entre otros ${ }^{3}$. Pero quizás la característica más elocuente de los apocalípticos es el exclusivismo salvífico; es decir, la creencia en que sólo ellos y su pequeño grupo poseen la verdad de Dios, y por tanto la salvación es su patrimonio exclusivo. Estos círculos apocalípticos huían del mundo y de su sistema corrupto. Un buen ejemplo serían los Esenios del Qumrán, secta judía que se ve confrontada con los poderes centrales del templo y decide huir al desierto para fundar el "Nuevo Israel".

Desde esta perspectiva se entiende al apocalíptico como un pesimista histórico, es decir, alguien que no tiene fe en que la historia se encamine hacia subien. Más bien, considera que este mundo y la sociedad no tienen salvación. El apocalíptico mismo se percibe como incapaz de hacer algo relevante por la sociedad, y por eso se aparta de ella, esperando la venida de Dios que pondrá fin a la maldad e instaurará un nuevo orden de paz y justicia.

Sin embargo, Misión Cristiana Roca Eterna es una iglesia que logra tomar conciencia de la realidad de sus comunidades y desarrolla programas de beneficio, que

3 Marco Teórico. Apartado III - Características Teológico - Literaria de la Apocalíptica, 19-23. van desde repartición de comida a los vagabundos, hasta ofertas de actividades remuneradas para los que se encuentran desempleados. En este caso, la apocalíptica ha sido un impulso que los motiva a trabajar para beneficio de su comunidad, en vez de convertirse en una fuerza alienante. Por tanto, la vivencia plena de una cosmovisión apocalíptica no impide que el creyente, en tanto ciudadano, participe activamente en la creación de una comunidad más justa y solidaria. El cristiano apocalíptico puede dar grandes aportes a beneficio, no sólo de la iglesia, sino de la sociedad entera.

A continuación se presenta un cuadro comparativo entre una perspectiva integral de la apocalíptica y la perspectiva tradicional:

\begin{tabular}{|l|l|}
\hline \multicolumn{1}{|c|}{$\begin{array}{c}\text { Apocalíptica } \\
\text { Tradicional }\end{array}$} & \multicolumn{1}{c|}{$\begin{array}{c}\text { Apocalíptica } \\
\text { Integral }\end{array}$} \\
\hline $\begin{array}{l}\text { El sujeto no desarro- } \\
\text { lla una conciencia so- } \\
\text { cial. Es decir que per- } \\
\text { manece indiferente a } \\
\text { los problemas de su } \\
\text { comunidad e ignora } \\
\text { esta realidad. }\end{array}$ & $\begin{array}{l}\text { El sujeto toma con- } \\
\text { ciencia de los pro- } \\
\text { slemas que afectan a } \\
\text { personas que viven } \\
\text { en ella. }\end{array}$ \\
\hline $\begin{array}{l}\text { El sujeto no desarro- } \\
\text { lla una conciencia } \\
\text { ciudadana. Es decir } \\
\text { que los individuos no } \\
\text { se sienten parte de la } \\
\text { sociedad, ni cumplen } \\
\text { sus deberes cívicos. }\end{array}$ & $\begin{array}{l}\text { El sujeto cumple con } \\
\text { todos sus deberes y procura ser } \\
\text { un buen ciudadano } \\
\text { para predicar con el } \\
\text { ejemplo. }\end{array}$ \\
\hline $\begin{array}{l}\text { El sujeto se } \\
\text { considera incapaz de } \\
\text { incidir positivamente } \\
\text { en la comunidad, } \\
\text { considera que el } \\
\text { mundo es presa de } \\
\text { poderes diabólicos } \\
\text { que no puede } \\
\text { combatir }\end{array}$ & $\begin{array}{l}\text { que ayudar a los } \\
\text { más necesitados y } \\
\text { vulnerables de su } \\
\text { comunidad es un } \\
\text { deber cristiano que } \\
\text { debe cumplir. }\end{array}$ \\
\hline
\end{tabular}




\begin{tabular}{|l|l|}
$\begin{array}{l}\text { Existe una actitud } \\
\text { de espera pasiva: } \\
\text { la confianza está } \\
\text { puesta en lo que Dios } \\
\text { hará en su venida, a } \\
\text { futuro. }\end{array}$ & $\begin{array}{l}\text { Existe una actitud de } \\
\text { esperanza dinámica } \\
\text { y activa: la confianza } \\
\text { está puesta en lo que } \\
\text { Dios puede hacer a } \\
\text { través de sus siervos } \\
\text { en la realidad actual. }\end{array}$ \\
\hline $\begin{array}{l}\text { Posee ideas } \\
\text { exclusivistas acerca } \\
\text { de la salvación } \\
\text { y prácticas } \\
\text { discriminatorias. } \\
\begin{array}{l}\text { Considera que sólo } \\
\text { él y su grupo son } \\
\text { dignos de salvarse. }\end{array}\end{array}$ & $\begin{array}{l}\text { Posee ideas } \\
\text { inclusivas acerca } \\
\text { de la salvación. } \\
\text { Trata de influenciar } \\
\text { positivamente } \\
\text { a otros con su } \\
\text { ejemplo. No huye } \\
\text { de la realidad } \\
\text { social, económica y } \\
\text { política sino que la } \\
\text { asume y la enfrenta } \\
\text { por medio de una } \\
\text { denuncia profética y } \\
\text { cristiana. }\end{array}$ \\
\hline
\end{tabular}

\section{CONCLUSIONES Y RECOMENDACIONES}

Como resultado de la investigación de campo, y con los datos recopilados, organizados y analizados; y habiendo sido cotejados estos datos con aquellos obtenidos de la fundamentación teórica, producto de la revisión de fuentes documentales, se presentan conclusiones siguientes:

- La formación bíblica-teológica a nivel universitario permite que los pastores y líderes desarrollen una perspectiva apocalíptica integral que se caracteriza por la sensibilidad social y conciencia ciudadana; así como también la práctica y promoción de valores cristianos, entre éstos, la solidaridad.

- La perspectiva escatológica-apocalíptica que el pastor general ha desarrollado en Misión Cristiana Roca Eterna no es compartida por todos los miembros o feligreses, ya que muchos de ellos siguen comprendiendo los sím- bolos y elementos apocalípticos de una manera tradicional. Esto implica que el pastor general tendrá que buscar los mecanismos adecuados para fomentar sus perspectivas teológicas con eficacia en la congregación.

- La vivencia de una cosmovisión apocalíptica tradicional obstaculiza el desarrollo de una conciencia social y ciudadana en los individuos ya que éstos no se sienten parte de la sociedad y sus procesos.

- La cosmovisión apocalíptica integral no obstaculiza la toma de conciencia social y el desarrollo de programas de beneficio para la comunidad por parte de la iglesia local. Sin embargo, esta mentalidad debe ser orientada por medio del estudio bíblico-teológico y el estudio de la realidad nacional.

Finalmente, se extienden las siguientes recomendaciones dirigidas al pastor general y al liderazgo de Misión Cristiana Roca Eterna:

- Desarrollarlosmecanismosapropiados para discipular a los miembros o feligreses de la iglesia, de manera que se busque fomentar la vivencia de una cosmovisión apocalíptica integral con conciencia social y ciudadana.

- Generar las condiciones apropiadas para que todos los miembros o feligreses de la iglesia se involucren, dando su valioso aporte en los programas de asistencia social hacia la comunidad.

A pastores y líderes de iglesias evangélicas de Santa Tecla:

- Desarrollar una espiritualidad apocalíptica que les permita vivir sus tradiciones a plenitud, y que los motive a desarrollar conciencia social y 
ciudadana. El caso de Misión Cristiana Roca Eterna puede servir como modelo o parámetro para la vivencia de una apocalíptica integral.

- Motivar a los miembros o feligreses de sus iglesias a formar parte de los programas de ayuda social para la comunidad. El caso de Misión Cristiana Roca Eterna puede servir como modelo o parámetro para el desarrollo de programas de ayuda social auto sostenibles.

A otros investigadores interesados en este tema:

- Que los fenómenos religiosos como la cosmovisión apocalíptica sean abordados sin prejuicios por parte del investigador, tomando en cuenta los conceptos y significados que los participantes atribuyen a sus prácticas, respetando en todo momento sus tradiciones.

\section{FUENTES CONSULTADAS}

- Álvarez-Gayou, J. L. (2009). Cómo hacer investigación cualitativa. Fundamentos $y$ metodología. México: Paidós Educador.

- Aranda, P., Martínez, F., y Fernández, M. (1996). Literatura judía intertestamentaria. Navarra, España: Verbo Divino.

- Croatto, S. (1990). “Apocalíptica y esperanza de los oprimidos". Revista de Interpretación Bíblica Latinoamericana. 20 (7), pp. 9-12.

- Hernández Sampieri, R., Fernández Collado, C., Baptista, P. (2010). Metodología de la investigación. 5a Ed.

- $\quad$ Koch, K. (1972). Redescubriendo la apocalíptica. Londres: SCM Press.

- La Madrid, A., et. al. (2000) Historia, narrativa y apocalíptica. Navarra, España: Verbo Divino.
- Leipoldt, J., Grundmann, W. (1973). El mundo del Nuevo Testamento, Tomo I. Madrid: Cristiandad.

- Macho, D. (1984). Apócrifos del Antiguo Testamento, Tomo I. Madrid: Cristiandad.

- Pikaza, X. I. (1999). Apocalipsis. 2da ed. Navarra, España: Verbo Divino.

- Pikaza, X. I. (2005). Antropología bíblica, Tiempos de gracia. Salamanca, España: Madrilejo del Monte.

- Schussler, E. (2003) Apocalipsis, visión de un mundo justo. Navarra, España: Verbo Divino, pp. 77-85.

- Stam, J. (1999). Apocalipsis, Capítulos 1 al 5. Introducción y comentario. Buenos Aires: Kairos.

- Turner, V. W. (1988). El proceso ritual. Madrid: Taurus.

- Valles, M. (1999). Técnicas cualitativas de investigación social. Reflexión metodológica y práctica profesional. Madrid: Editorial Síntesis.

- Van der Jagt, K. (2005). Interpretación de la Biblia: acercamiento desde la antropología cultural. San José: SBU. 